\title{
OS EPISÓDIOS DE RITA PATRÍCIO
}

\author{
Gustavo Rubim \\ UNL
}

RESUMO: 0 texto propõe uma leitura do livro Episódios: da teorizaçõo estética em Fernando Pessoa, da autoria de Rita Patríicio. Datado de 2012, o livro só ficou realmente pronto e publicado em 2014. A leitura defende a originalidade deste exame minucioso dos textos de teoria estética e literária de Fernando Pessoa, tanto pela maneira como os trata autonomamente da obra poética e os estuda na sua escrita específica, quanto pelo efeito de deslocação dos tópicos habituais na análise do programa modernista português. A crítica do idealismo pessoano e da noção de obra enquanto totalidade orgânica são sublinhados enquanto gestos condutores de toda a pesquisa. Propõem-se articulaç̧eses com outros ensaios recentes que em Portugal procedem à revisão da crítica e da hermenêutica pessoana.

PALAVRAS-CHAVE: Fernando Pessoa. Obra. Teoria estética.

\section{EPISÓDIOS BY RITA PATRÍCIO}

ABSTRACT: The text proposes a reading of the book Episódios: da teorização estética em Fernando Pessoa, by Rita Patrício. The book is from 2012, and it only was really ready, and also published, in 2014. The reading defends the originality of this thorough examination of the texts about aesthetic and literary theory by Fernando Pessoa, either for the way as he deals with the texts, autonomously from the poetical work, and as he studies them in their specific writing, or for the effect of displacement of the habitual topics in the analysis of the Portuguese modernist program. The criticism of Pessoa's idealism, as well as of the notion of work as organic totality, are highlighted while conducting gestures of the whole research. It is also proposed articulations with other recent essays that in Portugal do the review of Pessoas' criticism and hermeneutics.

KEYWORDS: Fernando Pessoa. Work. Aesthetic Theory.

Gustavo Rubim é crítico literário e professor de literatura na Universidade Nova de Lisboa. 


\title{
OS EPISÓDIOS DE RITA PATRÍCIO
}

\author{
Gustavo Rubim
}

O que vou dizer não é só a apresentação, é também o esboço da minha leitura do ensaio Episódios: da teorização estética em Fernando Pessoa, de Rita Patrício. ${ }^{1}$ De vez em quando, desviarei talvez algumas passagens do livro para pontos que são especialmente do meu interesse. Penso que essa é a única maneira de tratar um livro como este, que entre outras coisas ensina que a leitura nunca resulta numa coincidência entre o lido e o leitor. Mas também nunca se confunde com o apagamento de uma assinatura por outra. Assim, a pessoa que assina esse livro, além de ensinar na Universidade do Minho, é uma reconhecida estudiosa de Fernando Pessoa, tendo nomeadamente trabalhado com Jerónimo Pizarro na edição do volume VIII da Edição crítica de Fernando Pessoa, Obras de Jean Seul de Méluret (2006), e trabalhando atualmente na equipa do projeto "Estranhar Pessoa: um escrutínio das pretensões heteronímicas", dirigido por António M. Feijó. O seu interesse pela teoria literária já se manifestara ao coeditar, com Carlos Mendes de Sousa, um volume de estudos em homenagem ao Professor V. M. Aguiar e Silva em 2004, com o título Largo mundo alumiado. E o seu trabalho de estreia foi já uma análise do discurso crítico no belo ensaio Conhecimento de poesia: a crítica literária segundo Vitorino Nemésio, editado em 2001.

Em Episódios estão traços de todos esses traços da assinatura de Rita Patrício e ainda aqueles que a distinguem enquanto crítica literária e enquanto pessoana. Em particular um equilíbrio, sempre mantido, entre o entusiasmo de estudar uma obra que é, por si mesma, interessante e apaixonante, e a reserva que mantém uma autêntica leitora crítica longe do mero elogio da obra que

\footnotetext{
${ }^{1}$ PATRÍCIO, Rita. Episódios. Da teorização estética em Fernando Pessoa. Braga/Famalicão: Centro de Estudos Humanísticos da Universidade do Minho/Edições Húmus, 2012. O presente texto reescreve um pouco a apresentação que fiz do ensaio em Lisboa, no dia 1 de fevereiro de 2015, e traz ainda algumas marcas, quer de um discurso feito para ser dito, quer de um estilo que não previa audiência especializada. Todas as notas foram acrescentadas para esta publicação. Os trechos citados serão referenciados entre parênteses após as citações.
} 
estuda e ainda mais longe de qualquer deferência ou reverência que tolhesse a minúcia com que a examina.

A ideia do livro de Rita Patrício é bastante aquela que está anunciada no subtítulo do livro: estudar, à parte, digamos assim, os exercícios de teoria estética produzidos por Fernando Pessoa. Isto implica obviamente suspender a atenção habitualmente dada à poesia de Pessoa e deslocá-la para uma parte das suas muitas páginas de prosa, uma parte que estamos mais ou menos habituados a reconhecer como importante desde que Jorge de Sena editou em 1946 as Páginas de doutrina estética de Pessoa, mas muito mais desde que em 1966 foram publicadas em Lisboa, as Páginas íntimas e de auto-interpretação e, sobretudo, em 1967, as Páginas de estética e de teoria e crítica literárias, em ambos os casos por Jacinto do Prado Coelho e Georg Rudolf Lind. Quer dizer, estamos habituados a ver essa parte da prosa pessoana valorizada pelos seus estudiosos e editores e, todavia, não estamos habituados à ideia de ver trabaIhada essa prosa independentemente do estudo da poesia e dos problemas colocados pela divisão de Pessoa nas assinaturas dos "heterónimos". E aí está a ideia que distingue o livro de Rita Patrício, ainda que nesse domínio ela pareça ter um antecedente no livro de Georg Rudolf Lind intitulado Teoria poética de Fernando Pessoa, que foi traduzido em Portugal em 1970.

Mas a ideia não se esgota aí. Para a perceber é preciso dar toda a atenção ao título deste livro: Episódios. É um título que faz lembrar os títulos, que citei, dos volumes onde está editada esta prosa teórica de Pessoa: Páginas de... Ou seja, a mesma impressão, sempre um pouco estranha, de uma conjunção entre a vontade de produzir teoria e a dispersão dos escritos e dos esforços em que essa vontade de Pessoa se manifestou. Da teoria só há páginas ou episódios, não há mais nada em Pessoa. Não há nada de comparável à Mensagem em poesia, por exemplo. Mas isso ainda não constitui a explicação essencial do título e da ideia de Rita Patrício. A essencial está em que esse título retoma um título de Fernando Pessoa: foi o próprio Fernando Pessoa quem projetou editar um volume de ensaios críticos cujo título seria Episódios. Esse projeto existe no espólio de Pessoa, dactilografado a azul com o título a vermelho, e é tardio, situando-o Rita Patrício, que o transcreve e edita no primeiro anexo do livro, em data posterior a 1932 (p. 361-362). A ideia de Pessoa era juntar escritos vários, o mais famoso dos quais era o conjunto de ensaios sobre "A nova poesia portuguesa" que ele publicou em 1912 e que ficou a marcar a própria estreia de Pessoa como autor na literatura portu- 
guesa. Mas o interessante é que nesse projeto, que tem a forma de um prefácio ao tal imaginado livro Episódios, Pessoa diz que eles são "episódios" porque não fazem "parte integrante da minha intenção de escrever". E isso por corresponderem a enco-mendas, "por serem de solicitação externa", nas palavras desse prefácio esboçado que só agora podemos ler. Como se a intenção de escrever, a intenção que cria com a escrita aquilo a que chamamos uma obra, fosse uma história maior e estes estudos críticos fossem só episódios que estabelecem, como também escreve Pessoa no mesmo lugar, "uma passagem subtil de um elemento do entrecho para outro".

Tem sentido, então, chamar-lhes episódios: a palavra torna-se sinónimo de passagens. Mas, além disso, Pessoa dá um segundo sentido à ideia do episódico e à possibilidade de relançar, reeditar o episódico, convertendo-o em livro: diz ele (e estou só a seguir aqui as primeiras páginas do ensaio de Rita Patrício) que em cada um dos estudos se serviu do assunto dele "para falar doutra coisa". Portanto, o episódico, que ao mesmo tempo é o teórico e o crítico, é aquilo que foi escrito para lá da encomenda, aproveitando a encomenda para outros fins, "para falar doutra coisa" - e essa coisa é que seria linda, dá vontade de acrescentar, citando o poema famoso e captando o sentido alegórico que Pessoa confere a estes escritos teóricos e críticos.

A ideia de Rita Patrício, no gesto de retomar o título e o projeto pessoano como sinal de um pensamento, não tem portanto nada a ver com a ideia de perceber as teorias que estão por trás dos poemas pessoanos, nem com a explicação de coisas tão famosas (e tão repetidas em aulas) como as que se chamam sensacionismo, paulismo, neo-paganismo, etc. Ou sequer com a ideia de inventar heterónimos ou de explicar por que é que se inventaram heterónimos. Isso é a história grande, a epopeia, o grande templo pessoano que já todos frequentámos um pouco; mas aqui trata-se (e vou citar a autora) de "não aceitando os pórticos indicados por Pessoa, entrar nas suas construções teóricas [...] através de portas menores e lê-las, não segundo o mapa que Pessoa nos legou, mas concentrando-me antes nos espaços que medeiam essas grandes salas pessoanas." (p. 20)

A importância desta deslocação está na confiança de que sem essas portas menores, sem essas passagens (teóricas), alguma coisa de essencial se perde porque: "É no episódico que se garantem as ligações entre as partes, a coerência possível do todo." (p. 20)

Trata-se, portanto, de ler com toda a atenção estes ensaios e estudos de 
Pessoa, uns publicados e outros não, grande parte deles inacabados ou só esboçados, explorando a possibilidade de que ainda não sabemos, por não os termos lido nunca com essa atenção, que relação eles mantêm com os poemas de Pessoa e seus heterónimos. Por isso mesmo o tal antecedente que seria o livro de Georg Rudolf Lind de 1970 é um falso predecessor, que Rita Patrício descarta com grande elegância e eficácia numa simples nota de rodapé, apenas porque nesse livro, onde se poderia esperar que a estudasse, Lind desvaloriza e deprecia explicitamente a prosa ensaística pessoana. Neste sentido, arrisco que Episódios marca um gesto inédito na leitura de Fernando Pes-soa, ou reformulando de maneira mais vincada: um gesto completamente inédito em toda a leitura de Fernando Pessoa produzida até hoje.

Dir-se-á que Rita Patrício não está sozinha neste tipo de gestos inéditos: está por exemplo bastante bem acompanhada por Pedro Sepúlveda no seu livro Os livros de Fernando Pessoa (Lisboa: Nova Ática, 2012) ou pelo colombiano Jorge Uribe na sua tese de doutoramento inédita (mas legível on-line) Um drama da crítica: Oscar Wilde, Walter Pater e Matthew Arnold lidos por Fernando Pessoa, defendida em 2014, com pleno êxito, na Faculdade de Letras da Universidade de Lisboa ${ }^{2}$. Só posso concordar, mas nesse ponto sublinharia ainda que Episódios é o texto da tese de doutoramento de Rita Patrício, defendida em 2009 na Universidade do Minho, ainda que o livro traga data de 2012 e na verdade só tenha sido posto a circular em 2014. Há, aqui, portanto, com este anacronismo involuntário, certa precedência, certa antecipação, que não creio que se deva deixar de enfatizar. Ao mesmo tempo, seria caso para desenvolver aqui o tema da renovação atualmente em curso na leitura de Pessoa; não o podendo fazer (ficará para outra ocasião), quero só sublinhar que os três trabalhos que acabo de citar (incluindo Episódios) são dissertações de doutoramento, o que significa que o tipo de pesquisa e de dedicação que permite renovar a leitura - e portanto a nossa conversa com Fernando Pessoa e acerca do complicado universo que o nome de Pessoa implica - passa pelas condições de trabalho oferecidas pela universidade e pela energia crítica que permite à universidade dispensar a repetição do saber que ela mesma produz.

Como é que Rita Patrício nos guia pelo meio do labiríntico espólio pessoano à procura daquelas portas menores?

\footnotetext{
${ }^{2}$ LOZADA, Jorge Alberto Uribe. Um drama da crítica. Oscar Wilde, Walter Pater e Matthew Arnold, lidos por Fernando Pessoa. Tese de doutorado em Estudos da Literatura e da Cultura, Universidade de Lisboa, Lisboa, 2014.
} 
O livro também tem uma estrutura imprevista, nada convencional nem óbvia.

Depois da introdução, longa - cerca de 35 páginas que acabam com o gesto muito inteligente de sublinhar que esta teorização estética é necessariamente uma teoria moderna da arte e uma teoria da arte moderna, especialmente da poesia e da literatura (que é o que em Pessoa tende a significar a palavra "arte"), acrescendo que moderno aqui significa descendente dos românticos e, para Pessoa, significa ser discípulo de Rousseau ou ter "a alma filha de Rousseau" porque Rousseau seria o "pai de todos nós" ${ }^{3}$ - após essa introdução vêm então os quatro episódios da aventura de Rita Patrício: $1^{0}$ "Da música"; $2^{\circ}$ "Da Imperfeição"; $3^{\circ}$ "Episódios metacríticos" e o $4^{0}$ "Da tradução: 'literary lessons'".

Notem que esta estrutura, fazendo cortes temáticos no interior dos muitos textos pessoanos, não nos faz confundir estes episódios com uma historiazinha contada data a data, ano a ano ou coisa que o valha, da evolução do pensamento teórico de Pessoa. Nunca ficamos esquecidos das datas - e isso é importante num escritor que deixou um espólio muito superior à obra publicada - mas nunca somos dominados por elas. E notem também que, por mais que procurem, não encontrarão em parte nenhuma um estudo sobre Pessoa com uma estrutura sequer parecida com esta que acabei de resumir. Isso é bastante importante: mostra que uma tese universitária continua a poder ser realizada (porque temos o poder de o fazer e porque não há nada que impeça) com o espírito livre de uma ensaísta que, cumprindo todas as exigências da pesquisa universitária, nem por isso deixa de inventar um livro próprio, uma forma assinada que nenhum modelo prescreveu. E mostra outra coisa não pouco importante: que a crítica literária e os estudos literários, aqui realizados numa das suas formas mais típicas (o estudo dum autor), estão longe de estar esgotados e estão muito longe de não dar origem a livros interessantes e originais. Para não me perder muito nesta observação digressiva, lembro só que há por aí, escritas no espírito do que poderíamos chamar estudos literários "puros", várias teses inéditas que, do ponto de vista do pensamento crítico, põem em grande evidência a irrelevância de não poucos trabalhos que, vivendo da pretensão de desprezar as exigências da literatura, já nada mais têm para enfrentar hoje do que a vergonha de estarem publicados. Para a leitura

\footnotetext{
${ }^{3}$ As afirmações lêem-se num texto de Pessoa que está também integralmente transcrito como anexo 3 de Episódios, p. 363-365, incluindo a descrição material e o aparato genético.
} 
paciente de textos de natureza teórica, como a que empreende Rita Patrício, não se ganharia absolutamente nada em tomar o rumo equívoco apontado em tempos num título de Anthony Easthope - Literary into Cultural Studies que desde 1991 está condenado a figurar o esfarrapado fantasma do vanguardismo no ocaso do século $X X$.

Regressando, depressa, ao caminho principal, opto por destacar, para cada um dos episódios de Rita Patrício, uma ideia apenas, deixando desde já bem claro que a leitura integral do livro envolve um número amplo de ideias em cada episódio, se bem que sempre dominado por um fio condutor que nunca faz perder a linha de inteligibilidade do que está em discussão.

No episódio "Da Música", cuja matéria de base são as várias hierarquias das artes que Pessoa foi escrevendo ao longo da vida, talvez com predomínio desse texto cada vez mais importante que é Heróstrato ${ }^{4}$, destaco a maneira como o ponto de partida romântico de Pessoa é trabalhado em confronto direto com grandes pensadores da arte no século XIX, nomeadamente Hegel e Schopenhauer. É muito interessante ver como este assumido "filho de Rousseau" se vai revelando afinal sobrinho da estética hegeliana e do seu privilégio do Espírito, que para Pessoa quase só está na poesia.

Espírito ou ideia, porque ideia é capaz de ser a palavra mais recorrente em Pessoa para valorizar a literatura e a poesia face a todas as outras artes, parte das quais ele condenou a não terem sequer existência futura, a desaparecerem por esgotamento de funções. Ora, daí resulta uma das linhas mais interessantes do estudo de Rita Patrício, que é a sua perseguição intensiva, se posso exprimi-lo assim, ao idealismo de Fernando Pessoa. A intensidade marca-se na ligação muito forte que vai sendo estabelecida entre Pessoa e o século XIX e que levará a autora, na Conclusão do ensaio, a propor "pensar Pessoa [...] entre dois séculos, herdando as dilacerações do seculo XIX" (p. 335), uma forma de o entender que tem ganho solidez nas leituras mais recentes de Pessoa e que desfazem o mito de revolução ou de rotura modernista.

A marcação dessa ligação é em grande parte o resultado do primeiro episódio da aventura, o tal que se ocupa "Da música". A relação entre poesia e música é tópico recorrente na discussão das artes no século XIX: Pessoa valoriza a poesia e a literatura, mas o importante é o critério de valoração e esse critério passa decisivamente pelo poder de abstração, que seria constitu-

\footnotetext{
${ }^{4}$ PESSOA, Fernando. Heróstrato e a busca da imortalidade. Ed. Richard Zenith. Trad. Manuela Rocha. Lis-boa: Assírio \& Alvim, 2000.
} 
tivo da literatura, por força da própria natureza da palavra, da linguagem, que não existe sem abstração. Rita Patrício mostra com clareza as afinidades desta noção pessoana com a filosofia de Hegel, que é também (como se calhar toda a filosofia e em particular toda a filosofia moderna) uma filosofia da linguagem. Mas porquê defender a abstração? Porque a arte tem uma finalidade e essa finalidade é definida, a dada altura ou em vários momentos, como "elevar" e "libertar", isto é, elevar e libertar o homem, separando-o daquilo que não é humano. Por conseguinte, conclui a autora, "A libertação concedida pela abstração é um mergulho íntimo na essência do homem." (p. 73)

Portanto, o idealismo é um idealismo específico: depende de uma teoria do humano ou, se quiserem, depende duma antropologia. Este é um ponto muito importante: há uma antropologia pessoana que explica a sua ideia de literatura, ou a ideia de literatura de Pessoa não dispensa uma teoria da humanidade, do humano, da essência humana. A música, nesse sentido, é pouco humana, está muito dependente da emoção e, portanto, diz-se que ela é a pri-meira, mas no sentido em que já é a arte das aves, não precisa da humanidade para existir... (Seria interessante confrontar com Rousseau, para quem as aves não cantavam, ou seja, para quem esse "canto" das aves era apenas uma metáfora. Derrida, como se sabe, comentou essa distinção que não é mera distinção, mas hierarquia.)

Tal ideia da abstração, da inteligência abstrata sem a qual a literatura não existe e sem a qual a realização máxima da essência humana não acontece, conduz a um tópico que todos conhecemos muito bem de Pessoa: o tópico da universalidade, da língua e da obra que transforma a emoção ou sensação pessoal em entendimento impessoal. É a famosa lógica da despersonalização e da impessoalidade que é comum a Pessoa e a vários outros modernistas. Não vou insistir na importância da leitura deste tópico feita por Rita Patrício, senão num ponto: o que isto implica é a recusa do contingente ou, como ela escreve, voltando a introduzir o tema antropológico: "Tudo o que apareça como contingente [...] é aqui desvalorizado como matéria a exprimir. Neste quadro, à arte cabe a interpretação do homem, não dos homens." (p. 86) O idealismo pessoano está sempre portanto neste limite de uma antro-pologia essencial ou essencialista, de uma metafísica antropológica.

A parte final desta parte "Da música" mostra portanto como Pessoa reformula toda a teoria romântica da expressão pessoal ou individual. E irá dar à questão do ritmo. "O ritmo é o estilo do estilo" - é a grande frase de Pessoa 
que governa este bloco e é uma ideia que implica separar radicalmente o ritmo musical do ritmo poético, como se não tivessem nada a ver um com o outro. A poesia é uma disposição musical, rítmica, mas o que a governa não é o som, a materialidade do som: é a pausa. Do som e da música há um rasto na poesia, mas longínquo, sendo que essa distância é capital para a teorização estética de Pessoa.

Se me alonguei um pouco neste ponto, serei rápido no próximo.

E tanto mais rápido quanto "Da imperfeição" é um capítulo central de Episódios e podemos até chamar-lhe outra coisa, podemos dizer que ele desdobra a descoberta por Rita Patrício do imperfeccionismo pessoano. Eu escrevo a palavra "imperfeccionismo" no computador e o programa de texto sublinha-a de vermelho, aponta-ma como erro. Isso mostra como ela está certa, do ponto de vista crítico, porque é preciso inventá-la. Trata-se de um capítulo notável, onde se enfrenta a grande questão de Pessoa (grande, do ponto de vista dele, sem dúvida): a questão da obra. Imperfeição é o problema e a experiência da obra, é o problema e a experiência da escrita. A relação entre parte e todo, o poder de erguer a obra como um todo, a dificuldade de compor um todo, ou, para parafrasear uma frase de Pessoa que a autora comenta muito, a tortura do todo. É todo o problema de escrever, de compor, de ultrapassar o nível do fragmento, da coisa inacabada, que está aqui em causa. É muito clara a tese de Rita Patrício e, a meu ver, hoje indiscutível: Pessoa vive do desejo da unidade da obra, da obra como totalidade homogénea e portanto lamenta tudo o que lhe fica em fragmentos, que são, como ela diz, "estilhaços de uma unidade impossível, mas desejada" (p. 161). O próprio Livro do desassossego significa logo no título a vontade de dar forma de livro, isto é, de um todo orgânico e construído, a uma entidade como o desassossego. "O desassossego procurava aqui uma forma." (p. 161) Sabemos que não a encontrou senão pela mão de outros.

E aqui haverá alguma coisa de humano, do idealismo antropológico que eu referia? Há, há sempre. Porque a imagem mais forte dessa unidade orgânica da obra que Pessoa formula é a da obra como "ser humano": "Poder construir, erguer um Todo, compor uma coisa que seja como um corpo humano, com perfeita correspondência nas suas partes" (p. 164) - é uma das imagens mais fortes desse ideal radical de obra, ainda por cima formulada numa das páginas escritas para o Livro do desassossego. Aqui já não temos só no palco crítico, contracenando com Pessoa, Hegel ou Schopenhauer, mas também Baudelaire, 
Proust, Aristóteles, Valéry. E na forma de falhanço sempre repetido deste desejo de todo, aquilo que Rita Patrício sublinha é o "idealismo estreme" de Pessoa: aquele ser humano nunca se chega a compor, ou fica sempre como estátua grega partida, para mencionar outra imagem pessoana citada e comentada no ensaio.

Na sequência ou na sombra desta radical reflexão sobre a obra e o seu falhanço também tem de haver em Pessoa uma reflexão sobre a crítica, ou seja, "episódios metacríticos", que formam então o terceiro episódio da aventura.

O traço que liga os dois temas, subterraneamente na minha leitura, é o traço que diz respeito ao tempo. O fundamental deste capítulo estará nas páginas sobre a importância da ideia de história literária para Pessoa, visível desde os ensaios de 1912 sobre "A nova poesia portuguesa", publicados na Águia, de Teixeira de Pascoaes. O ponto de partida é novamente romântico, novamente o século XIX e depende da divisão da literatura em histórias nacionais, mais do que em divisões de épocas ou períodos histórico-literários (que no entanto Pessoa usa abundantemente, sobretudo em 1912). Mas onde a ligação é mais clara - e creio que é aqui estabelecida com uma nitidez invulgaríssima - é na interferência da noção de génio: o génio faz a literatura romper com a época presente e com o meio em que nasce e dirige a literatura na direção do futuro. O génio é, portanto, se bem entendo, uma figura central da teoria da modernidade em Pessoa, enquanto "antecipador do futuro", o que também corresponde a uma das grandes angústias pessoanas, que é a angústia da permanência da arte e da literatura para lá do tempo em que nascem. Naturalmente, Heróstrato regressa à cena de leitura e ao seu centro, agora para verificar certa oscilação ou dilaceração entre um tema saturniano e um "sonho jupiteriano", porque "se o tempo sempre devora os seus filhos, aqueles que se tornam, eles mesmos, criadores de um tempo novo [...], sendo origem de um futuro, escrevem o tempo." (p. 256) Citando assim apenas parte de um brilhante comentário, mal deixo uma ideia de como, deslizando entre Pessoa, Baudelaire e Valéry, a reflexão aprofunda aqui a asserção inicial que estabelecera a impossibilidade de desligar a teorização estética (e os seus impasses) de um discurso sobre a modernidade.

Estes temas todos ligam-se, por fim, sem milagre nem artifício, no último episódio: "Da tradução: 'literary lessons'”.

O capítulo é denso mas a noção básica parece ser a de que, para Pessoa, a 
tradução é no essencial uma superação de obstáculos e só é verdadeiramente tradução e verdadeiramente inte-ressante quando é difícil.

De certa maneira, o ponto é esse: Pessoa defende que a tradução, quando o é verdadeiramente, por exemplo a tradução de poesia lírica, é impossível e no entanto ele mesmo foi tradutor de poesia lírica. Repete-se, portanto, uma tensão, um movimento contraditório que vai no sentido de executar aquilo que se declara impossível de executar. Mas o próprio poema já era uma obra, em última instância, impossível de executar, e não esqueçamos que para Pessoa mesmo as obras de génio, como Hamlet ou King Lear ou Paradise Lost, exibem acima de tudo o mais os defeitos que resultaram da sua execução, isto é, aquilo que as impede de serem perfeitas. Tendo em conta que toda a teoria da obra, da escrita e da literatura é subordinada ao princípio de fins a cumprir que não se cumprem - ou seja, é teleológica, se bem que de uma teleologia persistentemente diferida - a simples noção de que traduzir implica, para Pessoa, adaptar os fins do autor do texto traduzido a fins que ele não teve, já implica, como mostra o comentário de Rita Patrício, que a tradução fica inscrita no coração do trabalho literário ou da experiência literária: para todos os efeitos, trata-se sempre de passar de uma língua para outra, de um sistema de fins para outro sistema de fins. É afinal o regresso de Babel, que de certa maneira é o problema principal de Pessoa, isto é, ao mesmo tempo a grande virtude e a grande complicação da literatura segundo Pessoa: que ela tenha de ser escrita ou expressa "numa língua qualquer".

Para não mais que sugerir onde essa reflexão nos conduz, aproximo, concluindo esta apresentação, duas frases do ensaio, concretamente do último capítulo, chamado "O poema sem corpo", cuja epígrafe é um excerto de Heróstrato: "and Babel is spread upon the world". Na primeira frase, escreve Rita Patrício: "É a própria natureza dos objetos literários - a de serem objetos em linguagem - que compromete uma suposta vocação de universalidade da arte literária [...]”. (p. 325)

E no fim, lemos:

Em muitos momentos [...] Pessoa afirma a premência dada à dimensão de artefacto da obra de arte, ao corpo que cada poema é, cuja perfeição tanto sonhou [...]. É só rasurando todo e qualquer corpo verbal que imagina, nessa ausência, o mais poderoso dos poemas: uma pura potência universal, que nenhuma matéria comprometeria. Descendente de Aristóteles, Pessoa também é filho de Platão. (p. 330) 
Concluo que ler a teoria estética pessoana não tem, portanto, qualquer efeito de esterilização ou de fechamento da leitura da sua poética. Faz, isso sim, com que, para a entender melhor, tenhamos de exultar muito menos com a sua afinal tão exagerada "modernidade". 